\title{
Charting Evolution's Trajectory: Using Molluscan Eye Diversity to Understand Parallel and Convergent Evolution
}

\author{
Jeanne M. Serb • Douglas J. Eernisse
}

Published online: 25 September 2008

(C) Springer Science + Business Media, LLC 2008

\begin{abstract}
For over 100 years, molluscan eyes have been used as an example of convergent evolution and, more recently, as a textbook example of stepwise evolution of a complex lens eye via natural selection. Yet, little is known about the underlying mechanisms that create the eye and generate different morphologies. Assessing molluscan eye diversity and understanding how this diversity came about will be important to developing meaningful interpretations of evolutionary processes. This paper provides an introduction to the myriad of eye types found in molluscs, focusing on some of the more unusual structures. We discuss how molluscan eyes can be applied to the study of evolution by examining patterns of convergent and parallel evolution and provide several examples, including the putative convergence of the camera-type eyes of cephalopods and vertebrates.
\end{abstract}

Keywords Mollusca $\cdot$ Eye $\cdot$ Pax6 $\cdot$ Camera-type eye $\cdot$ Evolution · Convergent evolution $\cdot$ Parallel evolution

The Mollusca is a large animal phylum, second only to the Arthropoda in the number of described living species. An estimated 100,000 species are distributed among seven classes: Aplacophora, Polyplacophora, Monoplacophora, Scaphopoda, Gastropoda, Cephalopoda, and Bivalvia (Ruppert et al. 2004). Each class is recognized by alternations to a basic molluscan body plan. For example, the arms and tentacles of a squid are a modification of the

\section{J. M. Serb $(\bowtie)$}

Department of Ecology, Evolution and Organismal Biology, Iowa State University,

253 Bessey Hall,

Ames, IA 50011, USA

e-mail: serb@iastate.edu

\section{J. Eernisse}

Department of Biological Science, California State University, Fullerton, CA 92834, USA muscular foot common in other molluscan lineages. The largest classes by far are Gastropoda (snails, slugs; 60,000 species) and Bivalvia (clams, oysters, mussels; 10,000 species). Polyplacophora (chitons) and Cephalopoda (squids, octopuses) are smaller classes, each containing nearly 1,000 species. Of the seven molluscan classes, it is these four classes that possess eyes.

Molluscan eyes are extremely varied, ranging from a simple eye cup or pit eye that is open to the environment to closed lens eyes much like those seen in fish (Fig. 1), compound eyes that superficially resemble the eyes of flies, pinhole eyes, and eyes with mirrors. In fact, molluscs have some of the greatest morphological diversity of eye types among all animals, with seven to 11 different lineages possessing eyes (von Salvini-Plawen and Mayr 1977). The size of molluscan eyes ranges from less than $0.02 \mathrm{~mm}$ (0.00078 in.) across in the diminutive small spot snail, Punctum minutissimum (Timothy Pearce, Carnegie Museum of Natural History, personal communication), to more than $27 \mathrm{~cm}$ (11 in.) across in the colossal squid (Mesonychoteuthis hamiltoni), about 11 times the size of a human eye (Black 2008; Lilley 2008).

In addition to the incredible diversity of eye structures and size range, the placement of eyes varies across molluscan taxa. Two of the four classes, gastropods and cephalopods, have a well-developed head (cephalic) region, so only they can have cephalic eyes, and most of them do, whereas Bivalvia and Polyplacophora have many replicated eyes in other parts of the body, such as along the ventral edge of the mantle or within a shell. Although many molluscan species possess light-sensitive structures, such as nerve endings in their epidermis as adults, and eye spots, a composite of light-sensitive and pigment cells as larvae, that are functionally important to the organism, we do not consider these to be true eyes. Instead, we define eyes as organs that can sense both light intensity and direction with 

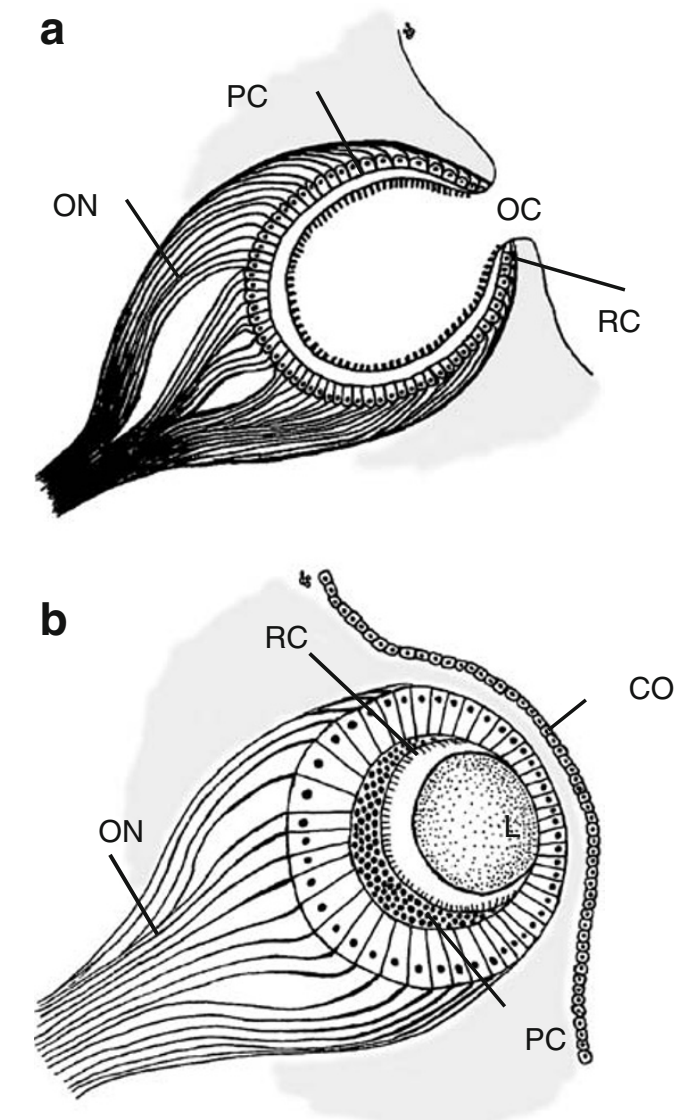

Fig. 1 Schematic drawing of two common eye types found in molluscs. An open pit eye in a does not have a lens or cornea and is open to the environment through an opening in the optical cup $(O C)$. The closed lens eye in $\mathbf{b}$ has both a lens $(L)$ and a cornea $(C O)$. Both eyes have optic nerves $(O N)$, photoreceptor cells $(R C)$, and pigment cells $(P C)$

the necessary components for at least rudimentary spatial resolution or image-forming capabilities.

\section{What Makes an Eye?}

At its most basic construction, an eye must have lightsensitive photoreceptor cells arranged in a cup shape and surrounded by pigment cells so that light from the environment can only hit a photoreceptor cell from one direction (Land and Nilsson 2002). Furthermore, a true eye can register light information from multiple photoreceptors simultaneously, and this information can be processed in parallel by the organism. Generally, the photoreceptor cells are arranged in a single layer to form a retina. These photoreceptor cells can be one of two types, identified by different ways of increasing cell surface area. If they have expansions on the ciliary membrane, they are ciliary photoreceptors, while rhabdomeric photoreceptors have extensions on the cell membrane as villi (Eakin 1979). Additional eye structures that are present in some eye types include a cellular or secreted cornea, lenses, vitreous masses, and reflective surfaces.

How well does an organism "see?" The functional performance of an eye is measured by its spatial resolution (the quality of the image) and by its sensitivity (ability to get enough light to the photoreceptors so that resolution is maximized; Land Nilsson 2002). Spatial resolution is determined by the spacing of the photoreceptors along the retina. In general, closer-packed photoreceptors provide a clearer image. Thus, the visual capabilities of organisms can be compared by calculating the resolving power of their eyes. Like other aspects of molluscan eyes, spatial resolution varies greatly among species (Table 1). For example, the resolution of gastropod eyes broadly overlaps with both vertebrate and arthropod eyes.

This paper provides an introduction to the myriad of eye types found in molluscs, highlighting some of the more unusual structures. We discuss how molluscan eyes can be applied to the study of evolution by examining patterns of convergent and parallel evolution and provide several examples, such as the putative convergence of the cameratype eyes of cephalopods and vertebrates and the similarity of compound eyes in the ark clams and arthropods.

\section{The Chitons (Polyplacophora) and Their Simple Photoreceptors}

The polyplacophorans (chitons) are multi-shelled marine molluscs often found attached to rocks on the seashore. Chitons respond to a bright directional light by moving away from it (Omelich 1967; Boyle 1972). In general, chitons tend to seek refuge under a rock during the day and emerge to forage at night, probably to avoid potential predators. They are also wary of shadows, for example, one that might be cast by a hungry bird. Their "shadow response" can be sudden. Crozier and Arey (1918) observed that a shadow of a fly 2 m away caused Chiton tuberculatus to stop temporarily in its trek across a rock. How does a chiton respond so quickly to a bright light or a shadow? Chitons (like most molluscs except the familiar cephalopods and gastropods) not only lack cephalic eyes but they also lack a head. They also lack a central nervous system and barely even have ganglionic swellings along their ladder-like nervous system. Chitons are the only molluscs to have a living outer layer of their calcium carbonate shell, and their primary sensory organs are either arranged in neat rows or more randomly scattered across the upper surface of their multiple shell plates (Blumrich 1891; reviewed by Fischer 1988; Eernisse and Reynolds 1994; Reindl et al. 1997; Schwabe and Wanninger 2006; 
Table 1 Spatial resolution of a selection of animal eyes angle $\Delta \rho$

\begin{tabular}{lc}
\hline Name & Resolution/inter-receptor angle $\left(\Delta \phi,^{\circ}\right)$ \\
\hline Eagle & 0.0036 (Land and Nilsson 2002) \\
Human & 0.007 (Land and Nilsson 2002) \\
Octopus (cephalopod) & 0.011 (Land and Nilsson 2002) \\
Cat & 0.05 (Land and Nilsson 2002) \\
Strombus luhuanus (gastropod) & 0.23 (Land 1981) \\
Honeybee & 0.95 (Land and Nilsson 2002) \\
Planorbaruis corneus (gastropod) & 1.4 (Zieger and Meyer-Rochow 2008) \\
Scallop (Pecten maximus, bivalve) & 1.6 (Land and Nilsson 2002) \\
Lymnaea stagnalis (gastropod) & 2.5 (Zieger and Meyer-Rochow 2008) \\
Littorina littorea (gastropod) & 4.5 (Land and Nilsson 2002) \\
Fruit fly & 5.0 (Land and Nilsson 2002) \\
Nautilus (cephalopod) & 8.0 (Land and Nilsson 2002) \\
Cepaea nemorais (gastropod) & 8.0 (Zieger and Meyer-Rochow 2008) \\
Trichia hispida (gastropod) & 13.0 (Zieger and Meyer-Rochow 2008) \\
Helix aspersa (gastropod) & 14.5 (Hamilton and Winter 1982) \\
Giant clam (Tridacna maxima, bivalve) & 20.0 (Land 2003) \\
Ark clam (Barbatia cancellaria, bivalve) & 32.0 (Nilsson 1994) \\
Planaria (flatworm) & 35.0 (Land and Nilsson 2002) \\
\hline
\end{tabular}

Vendrasco et al. 2008). These sensory organs (termed aesthetes or esthetes) have been demonstrated experimentally to be capable of photoreception, and in at least some chitons, they probably have other sensory capabilities as well. Much remains unknown about how chitons see their world, but it is likely that most chitons are capable of responding to light in an adaptive manner. It is possible that their often thousands of spaced aesthetes, in addition to similar organs in the soft tissues surrounding their shells, provide the entire exposed surface of the animal with a sort of giant compound eye, allowing a coordinated response.

Chitons have a long fossil record, and aesthetes are well known from some of the oldest fossil shell plates of chitons that lived over 400 million years ago (e.g., Vendrasco et al. 2004). Modern chitons typically have spaced macroaesthetes, each surrounded by multiple microaesthetes, and their similar appearance in ancient relatives implies that their function has long been important and conserved. All modern chitons have aesthetes, with or without added pigmentation. Two particular lineages of chitons have not only aesthetes but also much larger and complex sensory organ called an ocellus (Fig. 2a-c; Moseley 1885; Nowikoff 1907). The ocellus has a lens, a vitreous area, and a cup of retinal cells with microvillous rhabdomes (Boyle 1969); these provide all the components necessary for spatial vision. Ocelli are large enough to be seen with a naked human eye (unlike aesthetes), but they are most likely too small to form images on a retina. The ocelli are highly repetitive structures where a single individual of Onithochiton neglectus can have 411 to 1,472 ocelli in rows along all shell valves (Boyle 1969). Why have so many ocelli if they function similarly to the simple aesthetes? Both chiton species with or without ocelli are usually, but not always, nocturnal. Further, it ap- pears that most species will respond to low intensities of light, including moonlight, even if the individual lacks ocelli (Omelich 1967). Therefore, it remains a mystery what additional functions the ocelli might provide to those chitons with them.

Because fossil chitons with ocelli are younger than ten million years, it is likely that ocelli are among the most recently evolved of all animal eyes. Perhaps their study can provide insight into how an eye might evolve. By comparing across the species of chitons with ocelli and their nearest relatives, there is an opportunity to investigate stages in the transition between simple photoreceptors to meditate light response behavior and true eyes.

\section{More Complex (and More Kinds) of Eyes: The Bivalves}

Bivalves (clams, mussels, oysters) are laterally compressed organisms typically adapted for life within the sediment of marine and freshwater systems. In general, these headless animals are relatively immobile as adults, and when sensory organs, including the eyes, are present, they are found on exposed tissues. It is thought that bivalve eyes are primarily used to detect predators and elicit a defense response, creating a type of optical "burglar alarm" for the animal (Nilsson 1994). Many bivalves possess eyes along the ventral margin of their mantle, which lines the shell. These are called pallial eyes, in reference to a mantle or cloak (Gk. pallium; Fig. 2d). In some taxa (e.g., Cerastoderma edule), pallial eyes are associated with siphons used for respiration and filter feeding (Morton 2001) and are often the only part of the bivalve not buried within the substrate. Pallial eyes are highly repetitive structures numbering in the tens 
Fig. 2 Diversity of eye types in four molluscan classes.

a Dorsal view of the shell plates and ocelli of a chiton

(Polyplacophora: Tonicia lebruni). b, c Magnified views of ocelli on the anterior shell plate. d Highly repetitive pallial eyes along the mantle edge of the scallop (Bivalvia: Argopecten irradians).

e Cephalic eyes (Gastropoda: Strombus). f Camera-type eyes in the squid (Cephalopoda: Loligo). g Cuttlefish (Cephalopoda: Sepia). Images are copyrighted and used with permission by the following: a-c A. Draeger and D. Eernisse, d W. Capman, e H. Chaney, and f-g L. J. Friesen
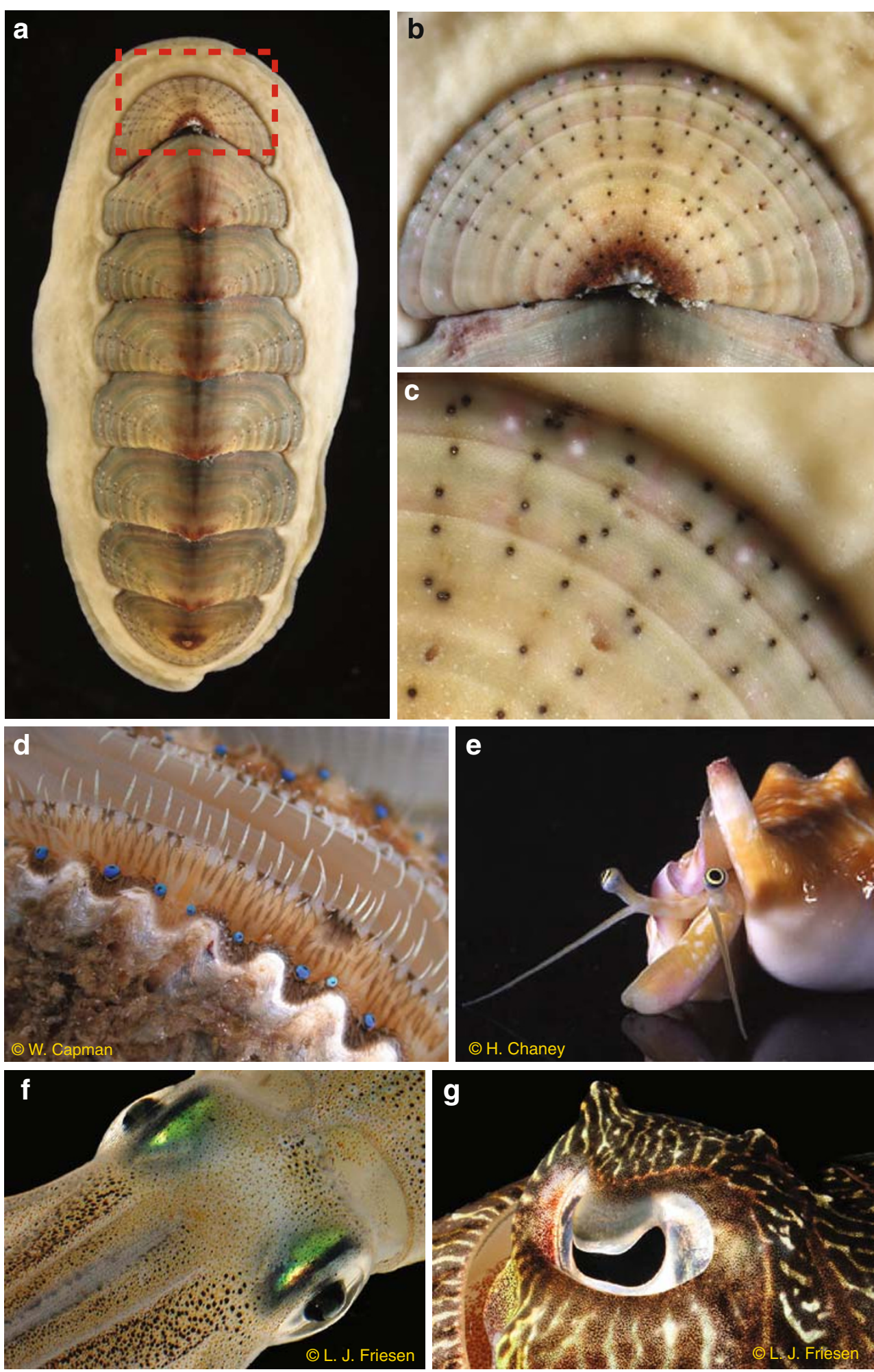

(Barber and Land 1967) to thousands (Wilkens 1986) per individual. Structurally, pallial eyes in bivalves are more diverse than cephalic eyes in other taxa. Pallial eyes can be either open pit or closed lens eyes (Fig. 1a,b), and some species may have several eye types along the mantle edge (e.g., Barbatia cancellaria). Some pallial eyes can have accessory organs that connect to the optic nerve and are adjacent to each eye (e.g., Cerastoderma edule, Tridacna maxima). Others may have single or double layers of photoreceptor cells, each composed of a different photoreceptor cell type (ciliary vs. rhabdomeric; e.g., Pectinidae, Laternulidae). In the giant clam, Tridacna maxima, pallial 
eyes not only sense the visual world (Wilkens 1988; Land 2003) but may also direct light to photo-symbionts living within the mantle tissue of the host (Fankboner 1981).

Two of the most complex and unusual eye types in bivalves are in the ark clams (Arcoida) and the scallops (Pectinidae). Two eye types are found in the ark clams, a simple cup eye and a multifaceted compound eye (Nilsson 1994; Patten 1887; Waller 1980). The compound eye is similar to the structure of the arthropod compound eye but is evolutionarily independent (Nilsson and Kelber 2007). An individual clam can have 200-300 compound eyes along the mantle edge. Current research suggests that the large number of eyes found in the ark clams are used to detect motion rather than form images of the environment (Nilsson 1994). The numerous eyes provide a more complete visual coverage of the bivalve's environment and better sensitivity to visual signals (Nilsson 1994).

The blue eyes of the scallop are among the best-known molluscan eyes (Fig. 2d). These eyes are lined with a sheet of guanine crystals that creates a concave mirror in the back of the eye. It is this mirror that forms an image of the environment by a reflection from the back of the eye onto a double retina directly behind the lens (Land 1965, 1984). Each retina is composed of different photoreceptor cells, ciliary photoreceptors in the distal retina, and rhabdomeric photoreceptors in the proximal retina. Experimental work on behavior and physiology has demonstrated that scallops respond to the distribution and intensity of light and can detect moving objects (von Buddenbrock and Moller-Racke 1953). There is also evidence that scallops use visual cues to discriminate between environments and to direct their swimming (Hamilton and Koch 1996) or adjust feeding behavior relative to the size of particles they see suspended in the water (Speiser and Johnsen 2008).

\section{Expanding Eye Diversity: The Gastropods}

Gastropods (snails, slugs) have a wide variety of eye types ranging from simple pit eyes without lenses or corneas to complex lens eyes (see reviews in Messenger 1981; Charles 1966; Chase 2002; Bobkova et al. 2004; Zieger and MeyerRochow 2008). Most gastropods have a pair of cephalic eyes which can be at the base of cephalic tentacles, on the tips of retractable tentacles so that the eye can be withdrawn into the tentacle, or on short stalks (Fig. 2e).

In addition to cephalic eyes, there are several unique sensory structures in the gastropods. Some pulmonate gastropod lineages, such as the terrestrial slugs (e.g., Limacidae), possess a double eye. This is a ventral extension of the retina composed of photoreceptor cells and un-pigmented supporting cells. When a lens is on this structure, it is treated as a second "eye" (Tamamaki 1989), while a lensless extension is called an "accessory retina" (Henchman 1897; description in Zieger and Meyer-Rochow 2008). It has been hypothesized that this structure may be involved in infrared detection (Newell and Newell 1968), but this has not been physiologically verified. Others have suggested that the two retinas of the double eye are used under different light intensities, thus expanding visual capability of the organism in a range of light conditions (see discussion in Kataoka 1977). Further research is needed to better understand the function of the double eye.

In some species of marine slugs (Onchidium), individual animals possess two eye types. The first type is a pair of cephalic eyes structurally similar to other lens eyes of gastropods (Katagiri et al. 1995). The second eye type is a lens eye that projects from the back of the animal (Hirasaka 1922). Each of the dorsal eyes is an open vesicle, spherical in shape, with a cup-shaped pigment layer, a ciliary-based retina, and lens, but lacks a cornea. These eyes appear to have image-forming capabilities and may create a "reasonable image" (Arey and Crozier 1921; Land 1968). See detailed descriptions of both eye types in Katagiri et al. (2002) and references therein.

Probably the most sophisticated and unique eye in the gastropods is the much-elongated "telescopic" eye of pelagic heteropods. These mobile carnivores spend their entire life cycle in the water column and possess many adaptations to this lifestyle, including a reduction or loss of shell, the modification of the muscular foot into a fin, and development of perhaps the most efficient gastropod eye (reviewed by Lalli and Gilmer 1989). Unlike the typical gastropod retina, the heteropod retina does not form a cup; rather, it is a long strip of three to six cells in width, resulting in a very narrow field of view. These eyes move in a systematic scanning motion, which may be used to detect prey (see Land 1982 for description). Even the composition of the heteropod retina is unusual and may contain several photoreceptor types that are unlike ciliary or rhabdomeric receptors found in cephalic eyes of other molluscs (Land 1984).

\section{Specialized Eyes: The Cephalopods}

Cephalopods (nautilus, squid, octopus) are a lineage of highly specialized predators. More than any other mollusc group, cephalopods rely on vision for prey capture, predator avoidance, and communication (Budelmann 1996; Hanlon and Messenger 1996; Muntz 1999; Hanlon 2007). Therefore, it is no surprise that these animals possess eyes with excellent perception and visual acuity (Messenger 1981).

There are two well-known cephalopod eye types. The pinhole eye type is only found in pearly nautiluses (Nautilidae), recognized by their chambered shell. The 
nautiloids and the similar but long-extinct ammonoids were once dominant predators in ancient seas, yet their eyes are only known from the six surviving species of pearly nautiluses. The nautilus eye is unusual, as it is a chamber open to the environment and does not have a cornea or lens to focus light. Instead, these eyes appear to function like a pinhole camera (Hurley et al. 1978; Messenger 1981). In nautiloids, the iris forms a small adjustable opening (pupil). The light rays reflected off an object pass through the pupil and form an inverted image of the object on the retina at the back of the eye. All other living cephalopods belong to the coleoid (internal shelled) cephalopods and possess a camera-type eye (Fig. 2f,g). This eye optically functions in a manner similar to the vertebrate eye, making the cephalopod eye a putative example of convergent evolution (Packard 1972). The cephalopod eye resembles the all-rod eye seen in sharks, with similar optics, speed, sensitivity, and resolution (Packard 1972). Morphological similarities of the eyes include an iris, nearly circular lens, vitreous cavity, and photoreceptor cells that form the retina; however, the photoreceptors in the cephalopod eye are rhabdomeric, not ciliary as in vertebrate eyes (Young 1962).

Structurally, the cephalopod eye differs from the vertebrate eye. Cephalopods do not have a cornea, and the retina is everted so that the distal end of photoreceptive cells lies directly behind the lens and points toward incoming light. As a result, photoreceptor cells connect to the optic nerve behind the retina (Packard 1972). In the vertebrate eye, photoreceptive cells are behind transparent ganglion cells, reversing the orientation of the retina and creating a "blind spot," an area devoid of photoreceptor cells where the optic nerve passes through it (Nicol 1989). This means that unlike vertebrates, there is no "blind spot" in the cephalopod eye. Similarities and differences in morphology and development of the coleolid cephalopod eye and the fish eye have been reviewed extensively elsewhere (Packard 1972; Messenger 1981; Yamamoto 1985; Harris 1997; Land and Nilsson 2002).

\section{Convergent vs. Parallel Evolution}

From the preceding discussion, it should be clear that a myriad of eye types exists throughout the molluscs. Additionally, the same eye types appear in distinct groups of organisms. This brings up an interesting question: how did they come to be? To answer this question requires understanding the evolutionary processes that generated them and the paths by which they have originated. This is done by examining the patterns of convergent and parallel evolution.

Convergence is the independent evolution of similar structural or functional components in two or more unrelated or distantly related lineages. In other words, two lineages have evolved convergently if they started from different ancestral morphologies and evolved towards the same (adaptive) phenotype (Fig. 3a). For example, the wings in animals, such as birds, bats, and pterosaurs - an extinct group of flying reptiles-are convergent. These animals belong to different families and are distantly related (i.e., do not share a common ancestor). However, they arrive at similar phenotypic endpoints because the same laws of aerodynamics apply to determine wing shape and size necessary for flight. So while the general morphology is similar, structure and organization of these wings greatly vary [e.g., the bird wing is formed by the first three fingers that support flight feathers (fingers $4-5$ have been lost); the bat wing is formed by a thin flexible skin stretched over the fingers $2-5$; the pterosaur wing is formed by skin and other tissues attached to an elongated fourth finger and reinforced with closely spaced fibers].

In contrast, parallel evolution is indicated when two lineages originate from similar ancestral phenotypes and evolve in the same trajectory towards a similar endpoint (Fig. 3b; Revell et al. 2007). It is often assumed in parallel evolution that the same genes underlying developmental processes are involved in the morphological change in separate lineages. Further, some argue that these changes at the gene level might act to constrain the type of morphological change that can occur (Wake 1991; Gould 2002). Until recently, it was extremely difficult to test whether (or how) gene expression changed for most species involved in putative parallelisms. For this reason, most researchers apply a morphological definition of parallel evolution that relies on pattern and can be more broadly applied, rather than use a definition restricted by identification of similar genetic change.

Distinguishing between parallel and convergent evolution is important because each implies a pathway underlying the evolutionary change (character evolution). But are these two evolutionary pathways mutually exclusive? a

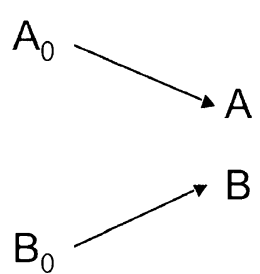

b

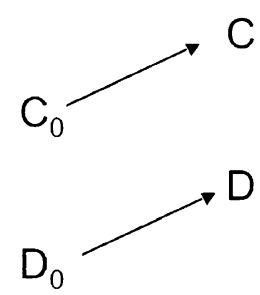

Fig. 3 Different evolutionary trajectories seen in convergent and parallel evolution. a In convergent evolution, ancestral phenotypes $\left(A_{0}\right.$ and $B_{0}$ ) are unalike but reach a similar endpoint in the descendent taxa $(A$ and $B) . \mathbf{b}$ In parallel evolution, ancestral phenotypes $\left(C_{0}\right.$ and $\left.D_{0}\right)$ are similar and evolve in trajectories towards similar endpoints in the descendents $(C$ and $D)$ 
Several authors have suggested a continuum between parallelism and convergence (Gould 2002; Donoghue 2005), which may result in instances of partial homology in an organ as a result of both convergence and parallel processes (for example, see Sattler 1991; Baum and Donoghue 2002). If this posit is true, it fits with the concept of biological systems organization in hierarchic levels (e.g., Vrba and Eldredge 1984). Just as an organism is composed of different organs, organs are made from tissue types, and tissue types are derived from specific cell types, the eye can be decomposed into component parts. Each of the levels or modules can have different histories and separate evolutionary trajectories (see examples in Serb and Oakley 2005) and therefore may exhibit either convergent or parallel patterns.

\section{What Can Molluscan Eyes Tell Us About Convergent and Parallel Evolution?}

For almost 140 years, the most cited example of convergent evolution was the likeness between the camera-type eyes of cephalopods and vertebrates (Darwin 1872; Packard 1972; Futuyma 1998; Land and Nilsson 2002). However, the idea that morphological similarity between cephalopod and vertebrate eyes is a result of convergence has been challenged by a growing number of researchers (Eakin 1979; Zuckerkandl 1994; Tomarev et al. 1997; Gould 2002). The strongest line of evidence against convergence is the discovery of a conserved gene network, including the gene Pax6 that governs eye organogenesis in vertebrate and invertebrate lineages (Quiring et al. 1994). One might suppose that if all animal eyes are regulated by the same gene network, then eyes must also share a common origin and that similarity between cephalopod and vertebrate eyes evolved as a parallelism due to constraint in development and not convergence. However, it is likely that the camera eyes of cephalopods and vertebrates have degrees of both convergent and parallel evolution. Eyes are not just single irreducible entities, but can be viewed as containing different levels of biological complexity nested in a hierarchical fashion (e.g., Serb and Oakley 2005). The eye can be subdivided into modules such as genetic networks (i.e., Pax6 network), photoreceptor cell types, crystallin proteins that make up the lens, phototransduction pathways that convert light into a chemical signal, and the eye itself as a morphological structure. Therefore, convergence may occur at one level, perhaps adult morphology of the eye, and parallelism may take place at other levels, such as genetic regulatory networks or photoreceptor cell types. Each module can be tested for convergent or parallel patterns.

Until recently, it was difficult to rigorously test these hypotheses. A new method developed by Revell et al.
(2007) distinguishes between convergence and parallelism using phylogenetic methods. This method incorporates morphological data on derived (extant) taxa and reconstructs the ancestral condition from the phylogeny. The path of phenotypic evolution is expressed as the difference between ancestor and descendant phenotypes for each lineage. These vectors are graphed, and their directions are compared to distinguish convergent and parallel patterns.

To accomplish these tests for cephalopod and vertebrate eyes, robust phylogenetic hypotheses of the cephalopods and the remaining Mollusca and the vertebrates within the Chordata would first be required. In addition, data must be generated from different eye modules for both molluscs and chordates. Ancestral phenotypes would be estimated from the extant taxa and the phylogeny. Changes in phenotypes from ancestor to descendent would be compared (as vectors) to other lineages at each level of biological complexity to develop a more complete estimation of evolutionary pattern.

Eyes from other molluscan lineages also could be used to study convergence and parallel patterns. For example, the compound eye in ark clams and arthropods would be an interesting comparison. Some work has been done on the cellular structure of the compound eyes of ark clams (Nilsson 1994; Nilsson Kelber 2007). However, nothing is known about the ark clam eye below the cellular level. Unlike the immense data on the compound eye of Drosophila, we know little to nothing of the developmental ontogeny, establishment of ommatidial patterning, or genetic mechanisms in eye organogenesis of the ark clams. Data from these modules will be necessary to test convergence and parallelism between molluscs and arthropods.

Other opportunities to study convergence or parallelism in Mollusca occur within classes, such as Gastropoda. As stated above, the eyes of gastropods range from simple eye pits to complex lens eyes. Although gastropod eyes have been used as a textbook example of Darwin's (1859) eye gradient to explain how an eye could evolve by natural selection (Strickberger 1990; Ridley 2003), these eye types have not been mapped on a phylogeny to formally test these assertions. It is likely that gastropod eyes do not fit a simple gradient of increasing complexity (see Fig. 1 in Oakley and Pankey 2008) but are instead characterized by a complex and interesting history involving multiple losses or gains of eyes, with similarities due to convergent and/or parallel evolution confounding those similarities due to common ancestry. One interesting example that needs further attention is the variation in retinal shape and optics across pulmonate gastropods (Meyer-Rochow and Bobkova 2001; Gál et al. 2004). In conclusion, patterns in eye evolution can only be properly evaluated as convergence versus parallelism by developing robust phylogenies paired with comparative studies of eye morphology across specific groups. 


\section{Summary}

Molluscs provide multiple opportunities to study the eye and general evolutionary processes. The incredible amount of phenotypic variation in molluscan eyes has been woefully underutilized by both evolutionary biologists and eye researchers. Future work on molluscs should include developing molluscan models to study ontogenetic progression (Serb 2008), expanding the knowledge of subcellular processes such as genomics and genetic regulation networks, and generating comprehensive phylogenetic hypotheses to identify patterns of convergence and parallelism.

Acknowledgments We are grateful to T. Ryan Gregory for inviting us to participate in this special issue on eyes. Dustine Pruszko prepared the drawings in Fig. 1. We thank Kevin Roe, Autum Pairett, and Jill Hansen for comments on an earlier draft and Dean Adams and Nicole Valenzuela for insightful discussion. D.J.E. thanks Andrea Macaluso, Springer Office of Publication, for encouragement to attend the American Malacological Society 2007 symposium organized by J. M.S. on molluscan eye evolution in Antwerp, Belgium where this review article originated. This work is supported by a grant from the National Science Foundation (DEB-0614153) to J.M.S.

\section{References}

Arey LB, Crozier WJ. On the natural history of Onchidium. J Exp Zool 1921;32:443-502. doi:10.1002/jez.1400320305.

Barber VC, Land MF. Eye of the cockle Cardium edule: anatomical and physiological investigation. Experientia 1967;23:677-8.

Baum DA, Donoghue MJ. Transference of function, heterotopy, and the evolution of plant development. In: Cronk Q, Bateman R, Hawkins J, editors. Developmental genetics and plant evolution. London: Taylor and Francis; 2002. p. 52-69.

Black R. Colossal squid's big eye revealed. BBC News; 2008, http:// news.bbc.co.uk/2/hi/science/nature/7374297.stm, 30 April.

Blumrich J. Das integument der Chitonen. Z Wiss Zool 1891;52:40476.

Bobkova MV, Gál J, Zhukov VV, Shepeleva IP, Meyer-Rochow VB. Variations in the retinal designs of pulmonte snails (Mollusca, Gastropoda): squaring phylogenetic background and ecophysiological needs (I). Invertebr Biol 2004;123:101-15.

Boyle PR. Rhabdomeric ocellus in a chiton. Nature 1969;222:895-6. doi: $10.1038 / 222895 \mathrm{a} 0$.

Boyle PR. The aesthetes of chitons. 1. Role in the light response of whole animals. Mar Behav Physiol 1972;1:171-84.

Budelmann BU. Active marine predators: the sensory world of cephalopods. Mar Freshw Behav Physiol 1996;27:59-75.

Charles GH. Sense organs (less Cephalopods). In: Wilber KM, Yonge CM, editors. Physiology of Mollusca, volume II. New York: New York Academic Press; 1966. p. 455-521.

Chase R. Behavior and its neural control in gastropod Molluscs. New York: Oxford University Press; 2002.

Crozier WJ, Arey LB. On the significance of the reaction to shading in chiton. Am J Physiol 1918;46:487-92.

Darwin CR. Origin of species by means of natural selection. 1st ed. London: John Murray; 1859.

Darwin CR. On the origin of species by means of natural selection, or the preservation of favoured races in the struggle for life. 6th ed. London: John Murray; 1872.
Donoghue MJ. Key innovations, convergence, and success: macroevolutionary lessons from plany phylogeny. Paleobiology 2005;31:77-93. doi:10.1666/0094-8373(2005)031[0077:KICASM]2. $0 . \mathrm{CO} ; 2$.

Eakin RM. Evolutionary significance of photoreceptors - retrospect. Am Zool 1979; 19:647-53.

Eernisse DJ, Reynolds PD. Chapter 3. Polyplacophora. In: Harrison FW, Kohn AJ, editors. Microscopic anatomy of invertebrates, volume 5, Mollusca 1. New York: Wiley-Liss; 1994.

Fankboner PV. Siphonal eyes of giant clams and their relationship to adjacent zooxanthellae. Veliger 1981;23:245-9.

Fischer FP. The ultrastructure of the aesthetes in Lepidopleurus cajetanus (Polyplacophora: Lepidopleurina). Am Malacol Bull 1988;6:153-9.

Futuyma DJ. Evolutionary biology. 3rd ed. Sunderland, Massachusetts: Sinauer; 1998.

Gál J, Bobkova MV, Zhukov VV, Shepeleva IP, Meyer-Rochow VB. Fixed focal-length optics in pulmonate snails (Mollusca, Gastropoda): squaring phylogenetic background and ecophysiological needs (II). Invertebr Biol 2004;123:116-27.

Gould SJ. The structure of evolutionary theory. Cambridge, Massachusetts: Belknap; 2002.

Hamilton PV, Koch KM. Orientation toward natural and artificial grassbeds by swimming bay scallops, Argopecten irradians (Lamarck, 1819). J Exp Mar Biol Ecol 1996;199:79-88. doi:10.1016/0022-0981(95)00191-3.

Hamilton PV, Winter MA. Behavoural responses to visual stimuli by the snail, Littorina irrorata. Anim Behav 1982;30:752-60. doi:10.1016/S0003-3472(82)80147-4.

Hanlon R. Cephalopod dynamic camouflage. Curr Biol 2007;17: R400-4. doi:10.1016/j.cub.2007.03.034.

Hanlon RT, Messenger JB. Cephalopod behaviour. Cambridge: Cambridge University Press; 1996.

Harris WA. Pax-6: where to be conserved is not conservative. Proc Natl Acad Sci USA 1997;94:2098-100. doi:10.1073/pnas.94.6.2098.

Henchman AP. The eyes of Limax maximus. Science 1897;5:428-9.

Hirasaka K. On the structure of the dorsal eyes of Onchidium, with notes on their function. Annot Zool Jpn 1922;10:171-81.

Hurley AC, Lange GD, Hartline PH. The adjustable "pin-hole camera" eye of Nautilus. J Exp Biol 1978;205:37-44.

Katagiri N, Katagiri Y, Shimatani Y, Hashimoto Y. Cell type and fine structure of the retina of Onchidium stalk-eye. J Electron Microsc (Tokyo) 1995;44:219-30.

Katagiri N, Suzuki T, Shimatani Y, Katagiri Y. Localization of retinal proteins in the stalk and dorsal eyes of the marine gastropod, Onchidium. Zoolog Sci 2002;19:1231-49. doi:10.2108/zsj.19.1231.

Kataoka S. Ultrastructure of the cornea and accessory retina in a slug, Limax flavus L. J Ultrastruct Res 1977;60:296-305. doi:10.1016/ S0022-5320(77)80015-4.

Lalli CM, Gilmer RW. Pelagic snails: the biology of holoplanktonic gastropod mollusks. Palo Alto, CA: Stanford University Press; 1989.

Land MF. Image formation by a concave reflector in the eye of the scallop, Pecten maximus. J Physiol 1965;179:138-53.

Land MF. Functional aspects of the optical and retinal organisation of the mollusc eye. Symp Zool Soc Lond 1968;23:75-96.

Land MF. Optics and vision in invertebrates. In: Autrum H, editor. Handbook of sensory physiology, vision in invertebrates, volume VII/6B. New York: Springer; 1981. p. 471-593.

Land MF. Scanning eye movements in a heteropod mollusc. J Exp Biol 1982;96:427-30.

Land MF. Molluscs. In: Ali MA, editor. Photoreception and vision in invertebrates. Montreal: Plenum; 1984. p. 699-725.

Land MF. The spatial resolution of the pinhole eyes of giant clams (Tridacna maxima). Proc R Soc Lond B Biol Sci 2003;270:1858. doi:10.1098/rspb.2002.2222. 
Land MF, Nilsson DE. Animal eyes. Oxford University Press: Oxford; 2002.

Lilley R. Colossal squid has world's biggest eyes. Wellington, New Zealand: Associated Press. National Geographic News; 2008. http://news.nationalgeographic.com/news/2008/04/080430-APnew-zealand.html. 30 April.

Messenger JB. Comparative physiology of vision in molluscs. In: Autrum H, editor. Handbook of sensory physiology, volume VII/ 6C. Berlin: Springer; 1981. p. 93-200.

Meyer-Rochow VB, Bobkova MV. Anatomical and ultrastructural comparison of eyes of two species of aquatic, pulmonate gastropods: the bioluminescent Latia neritoides and the nonluminescent Ancylus fluviatilis. N Zeal J Mar Freshw Res 2001;35:739-50.

Morton B. The evolution of eyes in the Bivalvia. Oceanogr Mar Biol Annu Rev 2001;39:165-205.

Moseley HN. On the presence of eyes in the shells of certain Chitonidae, and on the structure of these organs. Q J Microsc Sci 1885;25:37-60.

Muntz WRA. Visual systems, behaviour, and environment in cephalopods. In: Archer SN, Djamgoz MBA, Loew ER, Partridge JC, Vallerga S, editors. Adaptive mechanisms in the ecology of vision. Dordrecht, The Netherlands: Kluwer; 1999. p. 467-84.

Newell PF, Newell GE. The eye of the slug, Agriolimax reticulatus (Müll.). Symp Zool Soc Lond 1968;23:97-111.

Nicol JAC. The eyes of fishes. Oxford University Press: Oxford; 1989.

Nilsson DE. Eyes as optical alarm systems in fan worms and ark clams. Philos Trans R Soc Lond B Biol Sci 1994;346:195-212. doi:10.1098/rstb.1994.0141.

Nilsson DE, Kelber A. A functional analysis of compound eye evolution. Arthropod Struct Dev 2007;36:373-85. doi:10.1016/j. asd.2007.07.003.

Nowikoff M. Über die Rückensinnesorgane der Placophoren nebst einigen Bemerkungen über die Schale derselben. $\mathrm{Z}$ wiss Zool 1907;88:153-86. pls. 110, 111 .

Oakley TH, Pankey MS. Opening the "black box": the genetic and biochemical basis of eye evolution. Evo Edu Outreach 2008;1(4). doi:10.1007/s12052-008-0090-3.

Omelich P. The behavioral role and the structure of the aesthetes of chitons. Veliger 1967;10:77-82.

Packard A. Cephalopods and fish: the limits of convergence. Biol Rev Camb Philos Soc 1972;47:241-307. doi:10.1111/j.1469-185X. 1972.tb00975.x.

Patten W. Eyes of Molluscs and Arthropods. J Morphol 1887;1:67-92. doi:10.1002/jmor.1050010105.

Quiring R, Walldorf U, Kloter U, Gehring WJ. Homology of the eyeless gene of Drosophila to the small eye gene in mice and aniridia in humans. Science 1994;265:785-9. doi:10.1126/ science. 7914031.

Reindl S, Salvenmoser W, Haszprunar G. Fine structural and immunocytochemical studies on the eyeless aesthetes of Leptochiton algesirensis, with comparison to Leptochiton cancellatus (Mollusca, Polyplacophora). J Submicrosc Cytol Pathol 1997;29:135-51.

Revell LJ, Johnson MA, Schulte IJA, Kolbe JJ, Losos JB. A phylogenetic test for adaptive convergence in rock-dwelling lizards. Evolution Int J Org Evolution 2007;61:2898-912. doi:10.1111/j.1558-5646.2007.00225.x.

Ridley M. Evolution. 3rd ed. Oxford: Blackwell; 2003.

Ruppert EE, Fox RS, Barnes RD. Invertebrate zoology: a functional evolutionary approach. 7th ed. Belmont, California: Brooks; 2004.
Sattler R. Process homology: structural dynamics in development and evolution. Can J Bot 1991;70:708-14.

Schwabe E, Wanninger A. Polyplacophora. In: Sturm CF, Pearce TA, Valdés Á, editors. The mollusks: a guide to their study, collection, and preservation. Boca Raton, Florida: American Malacological Society and Universal Publishers; 2006. p. $217-$ 28.

Serb JM. Towards developing models to study the disease, ecology, and evolution of the eye in Mollusca. Am Malacol Bull. 26 (in press).

Serb JM, Oakley TH. Hierarchical phylogenies as a quantitative analytical framework for evolutionary developmental biology. Bioessays 2005;27:1158-66. doi:10.1002/bies.20291.

Speiser DI, Johnsen S. Scallops visually respond to the size and speed of virtual particles. J Exp Biol 2008;211:2066-70. doi:10.1242/ jeb.017038.

Strickberger M. Evolution. Boston, Massachusetts: Jones \& Bartlett; 1990.

Tamamaki N. The accessory photosensory organ of the terrestrial slug, Limax flavus L. (Gastropoda, Pulmonata): morphological and electrophysiological study. Zoolog Sci 1989;6:877-83.

Tomarev SI, Callaerts P, Kos L, Zinovieva R, Halder G, Gehring WJ, et al. Squid Pax-6 and eye development. Proc Natl Acad Sci USA 1997;94:2421-6. doi:10.1073/pnas.94.6.2421.

Vendrasco MJ, Wood TE, Runnegar BN. Articulated Palaeozoic fossil with 17 plates greatly expands disparity of early chitons. Nature 2004;429:288-91. doi:10.1038/nature02548.

Vendrasco MJ, Fernandez CZ, Eernisse DJ, Runnegar BN. Aesthete canal morphology in the Mopaliidae (Polyplacophora). Am Malacol Bull 2008;25:51-70.

von Buddenbrock W, Moller-Racke I. Über den Lichtsinn von Pecten. Pubbl Stn Zool Napoli 1953;24:217-45.

von Salvini-Plawen L, Mayr E. On the evolution of photoreceptors and eyes. In: Hecht MK, Steere WC, Wallace B, editors. Evolutionary biology, volume 10. New York: Plenum; 1977. p. 207-63.

Vrba ES, Eldredge N. Individuals, hierarchies and processes: towards a more complete evolutionary theory. Paleobiology 1984;10:14671.

Wake DB. Homoplasy: the result of natural selection or evidence of design constraints? Am Nat 1991;138:543-67. doi:10.1086/ 285234.

Waller TR. Scanning electron microscopy of shell and mantle in the order Arcoida (Mollusca: Bivalvia). Smithson Contrib Zool 1980;313:1-58.

Wilkens LA. The visual system of the giant clam Tridacna: behavioral adaptation. Biol Bull 1986;170:393-408. doi:10.2307/1541850.

Wilkens LA. Hyperpolarizing photoreceptors in the eyes of the giant clam Tridacna - physiological evidence for both spiking and nonspiking cell-types. J Comp Physiol 1988;163:73-84. doi:10.1007/BF00611998.

Yamamoto M. Ontogeny of the visual system in the cuttlefish, Sepiella japonica: 1. Morphological differentiation of the visual cell. J Comp Neurol 1985;232:347-61. doi:10.1002/cne.902320307.

Young JZ. The retina of cephalopods and its degeneration after optic nerve section. Philos Trans R Soc Lond B Biol Sci 1962;245:118. doi:10.1098/rstb.1962.0004.

Zieger MV, Meyer-Rochow VB. Understanding the cephalic eyes of pulmonate gastropods: a review. Am Malacol Bull. 2008;26 (in press).

Zuckerkandl E. Molecular pathways to parallel evolution: I. Gene nexuses and their morphological correlates. J Mol Evol 1994;39:661-78. doi:10.1007/BF00160412. 